$\begin{array}{ll}\text { Research Square } & \begin{array}{l}\text { Preprints are preliminary reports that have not undergone peer review. } \\ \text { They should not be considered conclusive, used to inform clinical practice, } \\ \text { or referenced by the media as validated information. }\end{array}\end{array}$

\title{
Potential of Cold Plasma to Control Callosobruchus chinensis (Coleoptera: Bruchidae) in Chickpea Cultivars during Four Year Storage
}

F Pathan ( $\square$ fayajlpathan@rediffmail.com )

Institute of Chemical Technology

R. Deshmukh

Institute of Chemical Technology

U. Annapure

Institute of Chemical Technology

\section{Research Article}

Keywords: Cold Plasma treatment, Chickpea, Callosobruchus chinensis, Stored chickpea grains

Posted Date: March 16th, 2021

DOI: https://doi.org/10.21203/rs.3.rs-258940/v1

License: (c) (i) This work is licensed under a Creative Commons Attribution 4.0 International License. Read Full License 


\section{Abstract}

Cold plasma has proven itself as a promising method of food preservation by controlling food spoilage bacteria at very low temperatures. It is showing potential for insect control. Synthetic pesticides are mostly used to control Callosobruchus chinensis to which it has developed resistance. The prospective potential of cold plasma treatment to control pulse beetle infestation of chickpea in the storage for about 4 years of plasma treatment was studied. The four chickpea cultivars were treated with cold plasma at different power 40, 50, and $60 \mathrm{~W}$ each for 10, 15, 20 min. Plasma treated and untreated chickpeas were stored in an airtight ziplock pouch. At regular intervals, the grains were observed for infestation. It was found most effective in controlling the pulse beetle infestation of treated chickpea samples. While plasma untreated chickpeas were attacked and damaged mostly by pulse beetle within the first quarter of the storage study. To avoid the problems created by the use of pesticides cold plasma treatment is found to be the best alternative in the protection of chickpea invasion by pulse beetle during a longer storage period. The findings in the present research may be used for the preparation of legumes which may also soak and cook faster like quick-cooking legumes and preserved for years without invasion of pulse beetle.

\section{Introduction}

Through symbiotic nitrogen fixation, legumes derive their nitrogen requirement. They contribute annually $50-70$ million tonnes of nitrogen to the agricultural ecosystem ${ }^{1}$. The world grows and consumes chickpea (Cicer arientinum L.). India is a major chickpea-producing country. It produces $61.49 \%$ of global chickpea production with $0.951 \mathrm{t} /$ ha productivity $^{2}$. There is an extensive presence of stored product insects in milling, processing, and warehouse facilities ${ }^{3}$. During storage of chickpea seeds fungal contamination and callosobruchus infestation cause quantitative as well as qualitative losses ${ }^{4}$. The Bruchids Callosobruchus spp. are the main storage pest of chickpea. These occur in low numbers just before harvesting and grow to extremely high numbers during storage. These causes weight loss, lower germination potential, and affect its quality ${ }^{5}$. The High temperature and high relative humidity during storage, cause hard-to-cook phenomenon in grain legumes. The seed coat and cotyledon have a role in chickpea hardening ${ }^{6}$.

Insect species that act as pests of the food grains in the field and storage created challenges. The pesticide is costly ${ }^{7}$. These are responsible for the maximization of agricultural yield. But they get accumulated in soils, water bodies, and fruits and vegetables, etc. This has increased the risk to biodiversity and also to the heath of human being ${ }^{8,9}$. Honey Bees are boon for the biodiversity and economy through their pollination services in forests and crops. However, the use of pesticides has adversely affected queen production ${ }^{10}$. Which has the potential to disturb the honey bee ecosystem with the potential to disturb all other ecosystems including human beings. People are increasingly desirous to get food with low or no pesticide residues ${ }^{8}$. Reducing the pest with increasing natural enemies will modify the environment through conservation biological control ${ }^{11}$. Natural pest control can be increased to reduce dependence on pesticides for insect control. ${ }^{12}$.

Nowadays to avoid and reduce the problems created by synthetic pesticides the use of sex pheromones, genome editing technique, use of nanocarrier to introduce peptide which will interfere with the immunity and reproduction of insects, selection of suitable target genes based insect control strategy- RNA interface, Sterile Insect Technique, nanoencapsulation of botanical compounds, use bio fumigants, essential oils has been studied and tried at depth 7, 9, 13-18

Non-thermal plasma or cold plasma works at ambient temperature conditions. It generates energetic electrons that collide with gas molecules. This results in dissociation, excitation, and ionization of gas molecule ${ }^{19}$. Initially after suing plasma applications to medicine and biology ${ }^{20}$; agricultural applications ${ }^{21}$; it is used for insect control ${ }^{22}$. Through reactive oxygen stress in $P$. interpunctella larvae, it causes oxidative damage ${ }^{23}$. Pathogens and diseases affect agricultural production and the entire food industry. Synthetic fungicides are the only promising solution for the same till today. The cold plasma is a novel suitable solution for it ${ }^{24}$. Cold plasma is used for conditioning and microbiological decontamination of biomaterials including food ${ }^{25}$. Sarangpani et al., (2017) studied the degradation efficacy of pesticides in blueberries after $80 \mathrm{kV}$ and $5 \mathrm{~min}$ in an in-package high voltage dielectric barrier discharge plasma reactor ${ }^{26}$. Plasma treatment was found to be effective in improving the germination efficiency of seeds ${ }^{27}$. Plasma-treated tap water used for the control of mealybug (Planococcus citri) infestation ${ }^{28}$. It is used as an advanced oxidation process to degrade the pesticides ${ }^{29}$. Plasma generation device, plasma exposure time, plasma power, and the carrier gas composition, influence the type and concentration of reactive species (e.g. ROS and RNS) and the overall efficiency of cold plasma degradation for a specific pesticide or allergen. ${ }^{30}$. In rice, wheat, corn, barley and oats cold plasma treatment ably reduced fungi, bacteria, and their spores on grain surfaces. It detoxify mycotoxins and control insect pests ${ }^{31}$. The cold plasma improves seed germination, the yield of agricultural products food quality, and nutritional security by the use of surface sterilization and inclusion of active nutrients in the plant system. It does not create any environmental or health hazard issue ${ }^{32}$. Plasma treatment used to control confused flour beetle and Mediterranean flour moth ${ }^{33}$. The eggs, larval, and adult stages of red flour beetle (Tribolium castaneum, Coleoptera: Tenebrionidae) by NTP ${ }^{34}$.

Cold plasma processing has attracted many researchers nowadays through its effective outcomes in the field of food processing especially for storage insect or pests control. The objectives of the present investigation were to evaluate the $C$. chinensis effects during the storage period of cold plasma treated four chickpea cultivars and to recommend the additional advantages of plasma processing to the chickpea seeds like surface modification and subsequent high rate of moisture absorption, control of hard to cook phenomenon with improved soaking and cooking, improved germination, prevention of microbial or pathogen infection. The outcomes of this research will be helpful to preserve the chickpea for about more than 4 years and save the losses of chickpea due to C. chinensis.

\section{Results}

\section{Quarterly assessment of grain damage percentage}

Page 2/10 
There were no significant difference in the control samples for percent grain damage of all cultivars except Vishal (Table 1.) $($ Virat: $d . f .=2,6 ; F=0.0 ; p=1.0$, Vishal: d.f. $=2,6 ; F=0.0 ; p=1.0$, Rajas: d.f. $=2,6 F=0.0 ; p=1.0$ ). There were no significant difference in the treated samples for percent grain damage of all cultivars (Table 1.)

Quarterly assessment of grain weight loss percentage

There were significant difference in the control samples for grain weight loss of all cultivars except and Rajas (Table 1.) (Kripa: d.f. $=2,6 ; F=0.66 ; p=0.045$, Virat: d.f. $=2,6 ; F=0.13 ; p=$, Vishal: d.f. $=2,6 ; F=0.107 ; p=0.048$, Rajas: d.f. $=2,6 ; F=0.559 ; p=0.170)$. There were no significant difference in the treated samples for grain weight loss of all cultivars (Table 1.) (Kripa: d.f. $=2,6 ; F=1.842 ; p=0.045$, Virat: d.f. $=2,6 ; F=4.109 ; p=$, Vishal: d.f. $=2,6 ; F=0.574 ; p=$ 0.048 , Rajas: d.f. $=2,6 ; F=6.798 ; p=0.170)$.

There were no significant difference in the samples for grain weight loss in all the treatment times when treated at $40 \mathrm{~W}$ of cold plasma to Kripa (Table 1.) except 40 W 15 min treatment (Kripa control: d.f. =2, 6; $F=0.272 ; p=0.771$, Kripa 40 W, 10 min.: d.f. $=2,6 ; F=9.387 ; p=0.014$, Kripa 40 W, 15 min. d.f. =2, 6; $F=8.872 ; p=0.016$, Kripa $40 \mathrm{~W}, 20$ min. d.f. $=2,6 ; F=0.356 ; p=0.714)$. There were no significant difference in the samples for grain weight loss in all the treatment times when treated at $50 \mathrm{~W}$ cold plasma (Table 1.) (Kripa control: d.f. $=2,6 ; F=0.272 ; p=0.771$, Kripa $50 \mathrm{~W}, 10$ min.: d.f. $=2,6 ; F=0.797 ; p=0.493$, Kripa 50 W, 15 min. d.f. $=2,6 ; F=1.096 ; p=0.393$, Kripa 50 W, 20 min. d.f. $=2,6 ; F=1.190 ; p=0.367)$. There were no significant difference in the samples for grain weight loss in all the treatment times when treated at $60 \mathrm{~W}$ cold plasma (Table 1.) except $60 \mathrm{~W} 15 \mathrm{~min}$. (Kripa control: d.f. $=2,6 ; \mathrm{F}=0.272 ; \mathrm{p}=0.771$, Kripa 60 W, 10 min.: d.f. =2, 6; $F=1.250 ; p=0.352$, Kripa 60 W, 15 min. d.f. $=2,6 ; F=5.170 ; p=0.050$, Kripa 60 W, 20 min. d.f. $=2,6 ; F=0.089 ; p=0.916$ ).

There were no significant difference in the samples for grain weight loss in all the treatment times when treated to Virat at $40 \mathrm{~W}$ cold plasma treatment except for $10 \min$ (Table 1.). (Virat control: d.f. $=2,6 ; F=0.318 ; p=0.739$, Virat $40 \mathrm{~W}, 10$ min.: d.f. $=2,6 ; F=6.221 ; p=0.034$, Virat $40 \mathrm{~W}, 15 \mathrm{~min}$. d.f. $=2,6 ; F=2.215 ; p$ $=0.190$, Virat $40 \mathrm{~W}, 20 \mathrm{~min}$. d.f. $=2,6 ; F=2.616 ; p=0.152)$. There were no significant difference in the samples for grain weight loss in all the treatment times when treated at $50 \mathrm{~W}$ cold plasma (Table 1.) (Virat control: d.f. $=2,6 ; F=0.318 ; p=0.739$, Virat $50 \mathrm{~W}, 10$ min.: d.f. $=2,6 ; F=0.196 ; p=0.827$, Virat $50 \mathrm{~W}, 15$ $\min$. d.f. $=2,6 ; F=0.245 ; p=0.790$, Virat $50 \mathrm{~W}, 20$ min. d.f. $=2,6 ; F=1.204 ; p=0.364)$. There were no significant difference in the samples for grain weight loss in all the treatment times when treated at $60 \mathrm{~W}$ cold plasma (Table 1.) (Virat control: d.f. $=2,6 ; F=0.318 ; p=0.739$, Virat $60 \mathrm{~W}, 10 \mathrm{~min} .: \mathrm{d} . \mathrm{f} .=2,6 ; \mathrm{F}=1.703 ; \mathrm{p}$ $=0.260$, Virat $60 \mathrm{~W}, 15$ min. d.f. $=2,6 ; F=1.708 ; p=0.259$, Virat $60 \mathrm{~W}, 20$ min. d.f. $=2,6 ; F=0.111 ; p=0.897)$.

There were no significant difference in the samples for grain weight loss in all the treatment times when treated at $40 \mathrm{~W}$ cold plasma to Vishal (Table 1.) (Vishal control: d.f. $=2,6 ; F=0.318 ; p=0.739$, Vishal $40 \mathrm{~W}, 10$ min.: d.f. $=2,6 ; F=0.497 ; p=0.631$, Vishal $40 \mathrm{~W}, 15$ min. d.f. $=2,6 ; F=1.025 ; p=0.414$, Vishal $40 \mathrm{~W}, 20 \mathrm{~min}$. d.f. $=2,6 ; F=0.413 ; p=0.679)$. There were no significant difference in the samples for grain weight loss in all the treatment times when treated at $50 \mathrm{~W}$ cold plasma (Table 1.) (Vishal control: d.f. $=2,6 ; F=0.318 ; p=0.739$, Vishal $50 \mathrm{~W}, 10$ min.: d.f. $=2,6 ; F=0.612 ; p=0.573$, Vishal $50 \mathrm{~W}, 15$ min. d.f. $=2$, $6 ; F=0.893 ; p=0.458$, Vishal $50 \mathrm{~W}, 20$ min. d.f. $=2,6 ; F=0.119 ; p=0.890)$. There were no significant difference in the samples for grain weight loss in all the treatment times when treated at $60 \mathrm{~W}$ cold plasma (Table 1.) (Vishal control: d.f. $=2,6 ; F=0.318 ; p=0.739$, Vishal $60 \mathrm{~W}, 10 \mathrm{~min} .:$ d.f. $=2,6 ; F=2.900 ; p=$ 0.131 , Vishal 60 W, 15 min. d.f. $=2,6 ; F=0.515 ; p=0.622$, Vishal 60 W, 20 min. d.f. $=2,6 ; F=0.729 ; p=0.521$ ).

There were no significant difference in the samples for grain weight loss in all the treatment times when treated to Rajas at $40 \mathrm{~W}$ cold plasma (Table 1.) (Rajas control: d.f. $=2,6 ; F=0.713 ; p=0.527$, Rajas 40 W, 10 min.: d.f. =2, 6; F = 4.288; $p=0.070$, Rajas 40 W, 15 min. d.f. = 2, 6; F = 3.367; $p=0.105$, Rajas 40 W, 20 min. d.f. $=2,6 ; F=0.706 ; p=0.090)$. There were no significant difference in the samples for grain weight loss in all the treatment times when treated at $50 \mathrm{~W}$ cold plasma treatment except for 15 min. (Table 1.) (Rajas control: $d . f .=2,6 ; F=0.713 ; p=0.527$, Rajas 50 W, 10 min.: d.f. $=2,6$; $F=0.181 ; p=0.839$, Rajas 50 $W, 15$ min. d.f. $=2,6 ; F=13.02 ; p=0.007$, Rajas $50 \mathrm{~W}, 20$ min. d.f. $=2,6 ; F=2.865 ; p=0.134$ ). There were no significant difference in the samples for grain weight loss in all the treatment times when treated at $60 \mathrm{~W}$ cold plasma treatment. (Table 1.) (Rajas control: $d . f .=2,6 \mathrm{~F}=\mathrm{F}=0.713 ; \mathrm{p}=0.527, \mathrm{Rajas} 60 \mathrm{~W}, 10$ $\min .:$ d.f. $=2,6 ; F=1.914 ; p=0.228$, Rajas 60 W, 15 min. d.f. $=2,6 ; F=3.828 ; p=0.085$, Rajas 60 W, 20 min. d.f. $=2,6 ; F=2.937 ; p=0.129$ ).

Quarterly assessment of the number of eggs/grain

There were no significant differences in the control samples for number of eggs per grain of all cultivars (Table 1.) (Kripa: d.f. $=2,6 ; F=1.666 ; p=0.266$, Virat: d.f. $=2,6 ; F=0.094 ; p=0.912$, Vishal: d.f. $=2,6 ; F=0.527 ; p=0.615$, Rajas: d.f. $=2,6 ; F=0.843 ; p=0.476)$. There were no significant difference in the treated samples for number of eggs per grain of all cultivars (Table 1.)

Quarterly assessment of the number of holes/grain

There were no significant differences in the control samples for number of holes per grain of all cultivars except Vishal (Table 1.) (Kripa: $d . f .=2,6$; $F=0.613 ; p$ $=0.572$, Virat: d.f. $=2,6 ; F=4.742 ; p=0.058$, Vishal: d.f. $=2,6 ; F=17.106 ; p=0.003$, Rajas: d.f. $=2,6 ; F=1.705 ; p=0.259$ ). There were no significant difference in the treated samples for number of holes per grain of all cultivars (Table 1.)

There were no significant differences in the samples for number of holes per grain in all the treatment times when treated Vishal at $40 \mathrm{~W}$ cold plasma (Table 1.) (Vishal control: d.f. $=2,6 ; F=0.542 ; p=0.608$, Vishal $40 \mathrm{~W}, 20$ min. d.f. $=2,6 ; F=0.214 ; p=0.813$ ). There was no significant difference in the samples for the number of holes per grain in all the treatment times when treated at $50 \mathrm{~W}$ cold plasma. There was no significant difference in the samples for the number of holes per grain in all the treatment times when treated at $60 \mathrm{~W}$ cold plasma. (Table 1.)

\section{Discussion}

The plasma treatment was found significantly effective over control with regards to check the grain damage in most of the chickpea samples (Table 1 , Supplementary Table S1, and Supplementary Figure S1). Grain damage percentage in plasma untreated grains was much higher in the first quarter of the 
assessment. It was $100 \%$ in Kripa, $99 \%$ in Virat, $97 \%$ in Rajas, $95 \%$ in Vishal. While in plasma-treated grains except in Vishal (40 W, 15 , and 20 min) grain damage was from $1-3 \%$. While in rest all treated samples of all the cultivars the grain damage percent was found to be $0 \%$ in the entire storage period of the 48 months in all the treated grains after treatment with 40-60 Watts for10-20 min.

It is not that shorter wavelengths are always more toxic blue light was also lethal to flour beetles and mosquitoes. Highly toxic wavelengths of visible light are species-specific in insects ${ }^{35}$. There is no such specificity is required for the insect species while cold plasma is used to control it. Insecticide-treated and control plots are compared and it was found that in control that eco engineered plots there was an abundance of predators and parasitoids. In it, parasitism rates increased significantly. Farm bunds grown with flowers were compared with control farm bunds and it showed that significantly fewer principal pests and damage were found former than latter. Thus the study indicated that in rice farm habitat manipulation for natural enemies enhanced the pest suppression and maintained equal yields. It also reduced the need for insecticide use in crop fields ${ }^{8}$.

As compared to the plasma this system can be applied for pest control. But only if the seeds before sowing are treated with plasma can make those selfstable to fight with on-farm or in storage diseases and pests. Moreover, it also improves a wide range of qualities of seeds. Natural pest optimization can be obtained through establishing non-crop areas, temporal crop rotation control, and low-impact tillage, at local and landscape scales. They suggested that multiple enemies attack pests during different periods of their occurrence in the field which is responsible to improve biological control efficacy ${ }^{12}$.

Though it looks simple to suggest as above, the practices mentioned to maintain the landscape require discipline and unity in the farmers and to follow all the practices unanimously. When cold plasma can be used for pest control from sowing the seeds to harvested seeds. This will be the completion of one cycle of cold plasma use for pest and disease control. Many such cycles needed to make it and habit for generations of farmers. This will surely make pests disappear from landscapes forever and the use of pesticide and our dependence on it can be reduced magnificently. The process efficacy for a wide range of plasma applications, like antimicrobial, pesticidal, food functionalization, and waste treatment has been demonstrated through multidisciplinary scientific efforts ${ }^{26}$. The chitosan nanoparticles functionalized with $\beta$-cyclodextrin prepared which has carvacrol and linalool. The toxicity and biological activity were evaluated. The toxicity decreased when the compounds were nano-encapsulated ${ }^{9}$. No such problem of the requirement of encapsulation is required when cold plasma is used to treat the seeds to control the pest and diseases and subsequent reduction in toxicity to the pest.

The use of coconut oil (Cocus nucifera), ginger oil (Zingiber officinale), jojoba oil (Simmondsia chinensis), and spearmint oil (Mentha spicata) against the adult of red flour beetle. They found that in all stages of flour beetles' Tribolium castaneum (Herbst), $100 \%$ mortality can be achieved ${ }^{36}$. Results in our investigation for all the parameters viz. grain damage percentage, grain weight loss percentage, number of eggs/grain, and number of holes/grain are in close proximity with results obtained by Rahman et al. (2018) ${ }^{34}$. Only in cases where the number of holes/grain and the number of eggs per grain occurs in plasma treated samples, it may be due to the infestation of those samples before treatment, but non-occurrence of further damage of it shows the $100 \%$ control of plasma treatment over pulse beetle ${ }^{34}$.

Grain weight loss percentage in plasma untreated grains was much higher in the first quarter of assessment and thereafter it was occurred decreasing slowly throughout the storage period. It was $56.85-62.87 \%$ in Rajas, $56.83-62.86 \%$ in Vishal, $56.87-62.99 \%$ in Kripa, $58.14-62.64 \%$ in Virat. While in plasmatreated grains the weight loss percentage was found decreasing steadily as the bruising has been occurred to the grains due to plasma treatment in the entire storage period of 48 months. In Kripa it is decreased from 6.4-6.79\%, in Vishal 7.15-9.72\%, in Virat 9.05-10.53 \%, in Rajas $11.32-15.00 \%$ after treatment with 40-60 Watts for 10-20 min (Table 1, Supplementary Table S2 and Supplementary Figure S2)

The Trojan female technique a mutation in the mitochondrial cytochrome b gene (mt: Cyt-b) was studied ${ }^{7}$. It reduces male fertility. They further mentioned that the effects of this mutation were moderated by the nuclear background and thermal environment. The fertility of males carrying the mutation was invariably reduced relative to controls ${ }^{7}$.

Guo et al. (2015) ${ }^{16}$ cloned a novel ABC transporter gene PxABCH1 in diamondback moth, Plutella xylostella (L.). Czarniewska et al. (2019) showed the possibility to introduce a peptide to the interior of the insect body using a nanocarrier ${ }^{15}$. They predicted that it will interfere with the immunity and reproduction of insects (Czarniewska et al., 2019) ${ }^{15}$. Koutroumpa et al. (2016) investigated the olfactory receptor co-receptor Orco gene to find its function in Lepidoptera olfaction. Also, they mentioned Orco is essential for both host and mate detection in Lepidoptera. They demonstrated CRISPR/Cas 9 is a simple and highly efficient genome editing technique in noctuid pests. Strategies ${ }^{14}$. It does not seem practically feasible to carry out all the aforesaid methods or techniques like mutation, peptide introduction, or genome editing to control insects that act as a pest on-farm and in or during storage. Rather the technology like cold plasma can be invariably used for control of all the insects acting as a pest. Results in our investigation for all the parameters viz. grain damage percentage, grain weight loss percentage, number of eggs/grain, and number of holes/grain are near the results obtained by Rahman et al. (2018) ${ }^{34}$.

Loganathan et al. $(2011)^{37}$ used thermal disinfestation for insect control. They held Eggs, larvae, pupae, and adults at $42^{\circ} \mathrm{C}$ or $0^{\circ} \mathrm{C}$ for varying durations. They found that pupae and adults were equally heat tolerant. According to them LT 50 at $42^{\circ} \mathrm{C}$ for eggs, larvae, pupae, and adults were $18,57,78$, and $71 \mathrm{~h}$, respectively. The $\mathrm{LT} 50$ at $0^{\circ} \mathrm{C}$ for eggs, larvae, pupae, and adults were $3,8,10$, and $4 \mathrm{~d}$, respectively. Pupa was the most cold-tolerant stage. Comparing with thermal processing of insects plasma processing was found to be more effective as it is done at lower temperature and for less time ${ }^{37}$. Datura alba leaf extracts at $2.5 \%$ shown 33.5 and $45 \%$ mortality in T. granarium and S. oryzae after 7 days of exposure, respectively ${ }^{38}$. Spinosad controlled C. maculatus throughout the 6 months of cowpea storage whereas deltamethrin failed to control C. maculatus after 3 months of storage ${ }^{39}$. Ozone at higher concentrations like 47-106 ppm could damage equipment in only 2 months by corrosion. Therefore Jian et al. (2013) ${ }^{40}$ recommended ton use it $\leq 50$ ppm for control of stored grain pests in the stored grain industry. 
In plasma, untreated grains number of eggs/grain was much higher in the first quarter of assessment. It was $2.90 \%$ in Vishal, $3.12 \%$ in Rajas, $3.14 \%$ in Virat, $3.51 \%$ in Kripa. In plasma-treated grains the number of eggs/grain was found to be in Vishal ranging from 4.28 to $5.12 \%$, which might be laid before the plasma treatment, hence it remains constant on the grain without fertilization of eggs for the entire storage period in grains after plasma treatment with $40-$ 60 Watts for 10-20 min. While in plasma-treated samples remaining grains of all the cultivars the number of eggs/grain was found to be $0 \%$ in the entire storage period of the 48 months in plasma-treated grains with 40-60 Watts for 10-20 min (Table 1, Supplementary Table S3 and Supplementary Figure S3)

The LC50 and LC95 of the essential oil of $V$. arborea and $a$-bisabolo/ were 5.23 and $12.97 \mu \mathrm{L} L-1$ of air and 2.47 and $8.82 \mu \mathrm{L} L-1$ of air, respectively. Thus the Increased concentrations of the essential oil reduced the instantaneous rate of population growth, rate of development, oviposition, and the number of eggs of $C$. maculatus, and therefore they have the potential for pest control ${ }^{18}$. Seventy volatiles were identified from which the 6 putative attractants and 6 repellents were emerged out, useful biocontrol tools ${ }^{41}$.

Many plants cannot yield the essential oil more than $1 \%$ in this condition how to extract essential oil commercially because quintal of biomass can give only less than $1 \mathrm{~kg}$ essential oil. These all essential oils are very volatile in nature and hence these are also known as volatile oils. The process to produce these are costlier. Therefore when it has to be produced and used commercially, it will be available at very higher costs. How it is then accepted by farmers? Simply if in the coming days the seed manufacturing companies can treating their seeds with cold plasma treatment which will be able to control diseases and pests during storage and on the farm as a crop. Agricultural expansion at the cost of natural habitats is the era of human-dominated landscapes ${ }^{42}$. This domination which had created many problems by impacting the environment and lives of ourselves can be reversed if we can get greater outputs from cold plasma and we would able soon to use it commercially as the method of pest control.

The results in this experiment showing no egg /grain on plasma-treated chickpea are in confirmation with Shahrzad et al. (2015) who treated instar larvae among wheat grains. They further reported that the mortality reached $100 \%$ after $20 \mathrm{~s}$ for both the pests called confused flour beetle and Mediterranean flour moth $^{33}$. Rahman et al. (2018) investigated the effect and mechanisms of the low-pressure dielectric barrier where egg, larval, and adult stages of red flour beetle were treated by non-thermal plasma. In all flour beetles' stages, $100 \%$ mortality was achieved depending on the plasma exposure time and plasma intensity. Moreover, they stated that an optimal effect of plasma with an impact on all stages of $T$. castaneum was observed ${ }^{34}$.. Results in our investigation for all the parameters viz. grain damage percentage, grain weight loss percentage, number of eggs/grain, and number of holes/grain are in close proximity with results obtained by Rahman et al. (2018).

In plasma, untreated grains number of holes/grain was much higher in the first quarter of assessment. It was 24.23 in Virat, 24.6 in Vishal, 25.26 in Kripa, and 25.44 in Rajas. In plasma-treated grains the number of holes/grain was found to be very less in Vishal ranging from $0.01-0.02$, which might be bored by pulse beetle or bruchids before the plasma treatment, hence it remains constant on the grain for the entire storage period after its plasma treatment with $40-60$ Watts for 10-20 min. While in plasma-treated remaining grains of all the cultivars the number of holes/grain was found to be 0 in the entire storage period of the 48 months in grains after plasma treatment with 40-60 Watts for 10-20 min (Table 1, Supplementary Table S4 and Supplementary Figure S4)

The larvae which hatch from the eggs of the Callosobruchus species needed to penetrate in the seed to survive ${ }^{43}$. Most of the plasma-treated samples where no holes found on grain shows that in it the eggs are not hatched into larvae. The plasma-treated samples where holes are found in grain are so negligible, it indicates it might be possibly due to infestation of these samples before plasma treatment up to the larval stage, but it gets eradicated due to plasma treatment and no occurrence of subsequent life stages of pulse beetle exhibited. Mahendran et al. (2016) used, electrode gap ( 3 to $5 \mathrm{~cm}$ ), exposure time (1 to 5 $\mathrm{min})$, and applied voltage (1000 to $2500 \mathrm{~V}$ ) while studying mortality of Tribolium castaneum. They reported that there is a significant increase in the mortality rate of an adult with an increase in applied voltage, exposure time, and decrease in electrode distance ${ }^{22}$. The powders of $C$. camphora, 0 . basilicum, and $C$. ambrosioides were effective against T. granarium, while that of C. ambrosioides caused $100 \%$ adult mortality of T. castaneum (Nenaah and Ibrahim, 2011 ). The LC50 value of lambda-cyhalothrin to quercetin-fed $H$. armigera larvae was 2.39 -fold higher than the control. This indicates a reduced sensitivity to lambda-cyhalothrin ${ }^{44}$.

Wheat seeds a red flour beetles infestation were studied by Afsheen et al. (2019). Where cold plasma treatment is carried out at $800 \mathrm{~V}$ for 1 and 4 min. There the minimum grain weight loss is observed in plasma treated seeds as compared to the control. The minimum mortality rate occurred in the control seed and maximum at 4 min plasma treatment. Plasma treatment can be used against red flour beetles particularly for long-term storage by controlling the insecticidal effects ${ }^{45}$. The activity of essential oil from coriander essential oil against Tribolium castaneum studied by Islam et al. (2008) ${ }^{46}$. In their findings, C. sativum oil showed high repellent activity to the adults of T. castaneum, up to $90 \%$. C. sativum oil used $12 \mu \mathrm{g} / \mathrm{ml}$ shown repellency to $100 \%$ in a filter paper arena test. Results in our investigation for all the parameters viz. grain damage percentage, grain weight loss percentage, number of eggs/grain, and number of holes/grain are similar with the results obtained by Afsheen et al. (2019) and Rahman et al. $(2018)^{45,34}$.

In the present study, it can be stated that cold plasma processing is found significant to avoid pulse beetle growth, infestation, and feeding on the chickpea samples for about 4 years, which is a comparatively very long period after considering the nature of infestation and losses caused by pulse beetle.

\section{Materials And Methods}

\subsection{Materials}

The four chickpea cultivars Kripa, Virat (Kabuli) Vishal, Rajas (Desi) were procured from the Pulses Improvement Project, Mahatma Phule Krishi Vidyapeeth, Rahuri complying with relevant institutional, national, and international guidelines and legislation. All required chemicals were procured from $S \mathrm{D}$ fine chemicals and Hi-Media Mumbai, India. All chemicals and reagents were of analytical grades (purity 99.99\%). 
An in-house designed low-pressure glow discharge plasma with bell-jar symmetry was employed for plasma treatment. The walls of the reactor are made up of Pyrex glass with $3 \mathrm{~mm}$ of thickness. The base and the opening lid are made up of stainless steel. The electrodes used were made of aluminum which has a $20 \mathrm{~cm}$ diameter. The electrode distance inside the reactor was maintained at $3 \mathrm{~cm}$ during all the plasma treatments. The system is capacitively coupled with a radio frequency power source having a frequency of $13.56 \mathrm{MHz}$. The system pressure was initially achieved at $0.05 \mathrm{mBar}$ with samples in the system by using HHV vacuum pump ED-20 and the working pressure was adjusted to the optimized value of $0.5 \mathrm{mBar}$. The plasma glow was observed (Fig. 1). The plasma treatment on chickpea cultivars was done at 40,50, and $60 \mathrm{~W}$ each having an exposure time of 10,15 and 20 min.

\subsection{Procedure for Observation of pulse beetle infestation during storage}

The six chickpea cultivars were exposed to 40,50, and $60 \mathrm{~W}$ cold plasma treatment each having an exposure time of 10, 15, and 20 min. Plasma treated and untreated chickpeas 100 grains were stored in airtight zip lock pouches of each sample. Ziplock pouches were kept at room temperature. During the storage period, the individual pouches were opened and checked critically for the presence of eggs, larvae, or adult pulse beetles and damage caused by them, at an interval of 3 months. The observations were noted and used for further calculations.

\subsection{Quarterly assessment of grain damage percentage}

For determination of grain damage percentage.100-grains were taken from each zip lock pouch quarterly. The number of bored grains was measured. The percent grain damage was calculated using the following equation:

\section{Chikpea grain damage Percent $($ bored seed $)=($ Numberof bored seeds $) /($ Total number of seeds of sample $) \times 100$}

\subsection{Quarterly assessment of grain weight loss percentage}

For the determination of grain weight loss percentage, 100 -grains were taken from each zip lock pouch quarterly. Their weight is measured ${ }^{47}$. The percent weight loss was calculated using the following equation ${ }^{48}$ :

\section{Chickpea grain percent weight loss $=($ Initial Wt.of grains - Final Wt.of grains $) /($ Intial Wt.of grains $) \times 100$}

\subsection{Quarterly assessment of the number of eggs/grain}

For the determination of the number of eggs/grain, 100-grains were taken from each zip lock pouch quarterly. The presence of eggs of pulse beetles can be easily seen in infested pulses with the naked eye these are singly occurring yellow-colored, which became opaque when hatched ${ }^{49}, 50$. The eggs on grains were measured. The number of eggs/grain was calculated.

2.7 Quarterly assessment of the number of holes/grain

For determination of the number of holes/grain, 100-grains were taken from each zip lock pouch quarterly and grains with holes are counted. The number of holes/grain was calculated.

\section{Conclusion}

The cold plasma treatment has attained much importance in various areas of food processing. In the present era, scientists are finding practical alternatives to chemical fumigants. Among these alternatives like sex pheromones, genome editing technique, use of nanocarrier, Sterile Insect Technique, nanoencapsulation of botanical compounds, use bio fumigants, essential oils, use of thermal treatments, use of RNAi, for control of the storage pests, cold plasma treatment is found to be the best remedy for controlling the storage pests like pulse beetle or bruchids. Moreover, there are additional advantages of plasma processing to the chickpea seeds like its surface modification and subsequent high rate of moisture absorption, control of hard-to-cook phenomenon with improved soaking and cooking, improved germination, prevention of microbial or pathogen infection. It is providing prolonged storage to the pulses for few years which is otherwise difficult to store for few months. This research showed that cold plasma has an excellent resistive effect against $C$. chinensis and it can be used to control a wide range of storage pests to have sustainable storage pest control. Further studies are required to design and develop commercial and continuous cold plasma treatment machinery for the processing of chickpea grains on a commercial basis.

\section{Declarations}

\section{Author contributions}

FLP and USA conceived and designed the paper. FLP, USA, and RRD contributed different sections to the manuscript. USA revised it critically for important intellectual content.

\section{Acknowledgments}

We thank Pulses Research Center, MPKV Rahuri for providing the authentic seeds of six chickpea cultivars for this experiment. Pravin Bhushette gave helpful suggestions on earlier drafts of this manuscript. Ajinkya Trimukhe helped a lot in the plasma processing of samples. 


\section{Competing interests}

The author(s) declare no competing interests

\section{Data availability}

The authors declare that data supporting the findings of this study are available within the paper and its Supplementary Information files. Source data are provided with this paper.

\section{Human and animal rights}

The research did not involve human participants and/or animals.

\section{Ethical approval}

This article does not contain any studies with human participants performed by any of the authors.

\section{References}

1. Herridge, D. F., Peoples, M. B. \& Boddey, R. M. Global inputs of biological nitrogen fixation in agricultural systems. Plant. Soil. 311, 1-18 (2008).

2. FAOSTAT (2019). Statistical Database of the United Nation Food and Agriculture Organization (FAO) Statistical Division, Rome. Available at, http://www.fao.org/faostat/en/\#data/QC (2019).

3. Semeão, A., Campbell, J., Hutchinson, J., Whitworth, R. \& Sloderbeck, P. Spatio-temporal distribution of stored-product insects around food processing and storage facilities. Agriculture, Ecosystems \& Environment. 165, 151-162 (2013).

4. Kumar, A., Shukla, R., Singh, P., Singh, A. K. \& Dubey, N. K. Use of Essential Oil from Mentha arvensis L. to Control Storage Moulds and Insects in Stored Chickpea. Journal of the Science of Food and Agriculture. 89 (15), 2643-2264 (2009).

5. Davies, J. C. \& Lateef, S. S. Insect pests of chickpea and pigeonpea in India and prospects for control. Pages 319-331 in Proceedings, International Workshop on Grain Legumes, 13-16 Jan, 1975, ICRISAT, Hyderabad, India. Available from ICRISAT, Patancheru 502 324, AP, India(1975).

6. Reyes-Moreno, C., Okamura-Esparza, J., Armienta-Rodelo, E., Gómez-Garza, R. M. \& Milán-Carrillo, J. Hard-to-cook phenomenon in chickpeas (Cicer arietinum L): Effect of accelerated storage on quality. Plant Foods Hum Nutr. 55, 229-241 (2000).

7. Wolff, J., Tompkins, D., Gemmell, N. \& Dowling, D. Mitonuclear interactions, mtDNA-mediated thermal plasticity and implications for the Trojan Female Technique for pest control. Sci Rep. 6, 30016 (2016).

8. Ali, M. P. et al. Establishing next-generation pest control services in rice fields: eco-agriculture. Sci Rep. 9, 10180 (2019).

9. Campos, E. V. R. et al. Carvacrol and linalool co-loaded in $\beta$-cyclodextrin-grafted chitosan nanoparticles as sustainable biopesticide aiming pest control. Sci Rep. 8, 7623 (2018).

10. dos Santos, C., Acosta, A., Dorneles, A. \& dos Santos, P. \& Blochtein B. Queens become workers: pesticides alter caste differentiation in bees. Sci Rep. 6, 31605 (2016).

11. Eilenberg, J., Hajek, A. \& Lomer, C. Suggestions for unifying the terminology in biological control. Bio. Control. 46 (4), $387-400$ (2001).

12. Dainese, M., Schneider, G., Krauss, J. \& Steffan-Dewenter, I. Complementarity among natural enemies enhances pest suppression. Sci Rep. 7, 8172 (2017).

13. Witzgall, P., Kirsch, P. \& Cork, A. Sex Pheromones and Their Impact on Pest Management. J. Chem. Ecol. 36, 80-100 (2010).

14. Koutroumpa, F. et al. Heritable genome editing with CRISPR/Cas9 induces anosmia in a crop pest moth. Sci Rep. 6, 29620 (2016).

15. Czarniewska, E., Nowicki, P., Kuczer, M. \& Schroeder, G. Impairment of the immune response after transcuticular introduction of the insect gonadoinhibitory and hemocytotoxic peptide Neb-colloostatin: A nanotech approach for pest control. Sci Rep. 9, 10330 (2019).

16. Guo, Z. et al. The novel $A B C$ transporter $\mathrm{ABCH} 1$ is a potential target for RNAi-based insect pest control and resistance management. Sci Rep. 5, 13728 (2015).

17. Rajashekar, Y., Tonsing, N., Shantibala, T. \& Manjunath, J. 2, 3-Dimethylmaleic anhydride (3, 4-Dimethyl-2, 5-furandione): A plant derived insecticidal molecule from Colocasia esculenta var. esculenta (L.) Schott. Sci Rep. 6, 20546 (2016).

18. Moura, E., Faroni, L. R. D., Zanuncio, J. C., Farnandes, F. \& Prates L.H.F. Insecticidal activity of Vanillosmopsis arborea essential oil and of its major constituent a-bisabolol against Callosobruchus maculatus (Coleoptera: Chrysomelidae). Sci Rep. 9, 3723 (2019).

19. Calvo, T., Alvarez-Ordonez, A., Prieto, M., Gonzalez-Raurich, M. \& Lopez, M. Influence of processing parameters and stress adaptation on the inactivation of Listeria monocytogenes by Non-Thermal Atmospheric Plasma (NTAP). Food Res. Int. 89, 631-637 (2016).

20. Graves, D. The emerging role of reactive oxygen and nitrogen species in redox biology and some implications for plasma applications to medicine and biology, Journal of Physics D: Applied Physics, 45 (26), Article ID 263001(2012).

21. Ito, M., Oh, J. S., Ohta, T., Shiratani, M. \& Hori, M. Current status and future prospects of agricultural applications using atmospheric-pressure plasma technologies, Plasma Processes and Polymers, 15 (2), Article ID 1700073(2018).

22. Mahendran, R. Effect of cold plasma on mortality of Tribolium castaneum on refined wheat flour, in Proceedings of the 10th International Conference on Controlled Atmosphere and Fumigation in Stored Products (CAF 2016), pp. 7-11, New Delhi, India, November(2016).

23. Abd el-aziz, Mona \&, Mahmoud, E. \& Elaragi Ga. Non-thermal plasma for control of the Indian meal moth, Plodia interpunctella (Lepidoptera: Pyralidae). Journal of Stored Products Research. 59, 215-221 (2014). 
24. Ambrico, P. F. et al. Surface Dielectric Barrier Discharge plasma: a suitable measure against fungal plant pathogens. Sci Rep. 10, 3673 (2020).

25. Starek, A. et al. Evaluation of selected microbial and physicochemical parameters of fresh tomato juice after cold atmospheric pressure plasma treatment during refrigerated storage. Sci Rep. 9, 8407 (2019).

26. Sarangapani, C., Patange, A., Bourke, P., Keener, K. \& Cullen, P. J. Recent Advances in the Application of Cold Plasma Technology in Foods. Annual Review of Food Science and Technology. 9, 609-629 (2018).

27. Saberi, M., Modarres-Sanavy, S. A. M., Zare, R. \& Ghomi, H. Amelioration of Photosynthesis and Quality of Wheat under Non-thermal Radio Frequency Plasma Treatment. Sci Rep. 8, 11655 (2018).

28. Ten Bosch, L., Köhler, R., Ortmann, R., Wieneke, S. \& Viöl, W. Insecticidal Effects of Plasma Treated Water. International journal of environmental research and public health. 14 (12), 1460 (2017).

29. Moutiq, R., Pankaj, S. K., Wan, Z. \& Mendonca A.Keener, K. \& Misra N.N. Atmospheric Pressure Cold Plasma as a Potential Technology to Degrade Carbamate Residues in Water. Plasma Chem Plasma Process. 40, 1291-1309 (2020).

30. Gavahian, M. \& Khaneghah, A. M. Cold plasma as a tool for the elimination of food contaminants: Recent advances and future trends. Critical Reviews in Food Science and Nutrition. 60 (9), 1581-1592 (2020).

31. Kaur, M., Hüberli, D. \& Bayliss, K. L. Cold plasma: exploring a new option for management of postharvest fungal pathogens, mycotoxins and insect pests in Australian stored cereal grain. Crop and Pasture Science. 71, 715-724 (2020).

32. Joshi, H., Kumar, R., Meena, D. \& Yadav, P. C. Explosion of plasma technology in agriculture. Int J Chem Stud;: 6 (6), 2531-2536 (2018).

33. Shahrzad, M., Sohrab, I., Davoud, D., Siavash, T., Mahmoud, S. \& \& The effect of non-thermal plasma to control of stored product pests and changes in some characters of wheat materials. Journal of Biodiversity and Environmental Sciences. 7 (5), 150-156 (2015).

34. Rahman, M. M. et al. Mechanisms and signaling associated with Ipdbd plasma mediated growth improvement in wheat. Sci Rep. 8 (1), 10498 (2018).

35. Hori, M., Shibuya, K., Sato, M. \& Saito, Y. Lethal effects of short-wavelength visible light on insects. Sci Rep. 4, 7383 (2014).

36. Abdel-Rahman, Y. A. \& Mahmoud, M. A. Toxic and repellent effects of four plant oils against the red flour beetle (Tribolium casteineum Herbst). Journal of Plant Protection and Pathology. 9 (5), 277-281 (2018).

37. Loganathan, M., Jayas, D. S., Fields, P. G. \& White, N. D. G. Low and high temperatures for the control of cowpea beetle, callosobruchus maculatus (F.) (coleoptera: Bruchidae) in chickpeas. Journal of Stored Products Research. 47, 244-248 (2011).

38. Ali, A., Ahmad, F., Biondi, A., Wang, Y. \& Desneux, N. Potential for using Datura alba leaf extracts against two major stored grain pests, the khapra beetle Trogoderma granarium and the rice weevil Sitophillus oryzae. J Pest Sci. 85, 359-366 (2012).

39. Sanon, A., Ba, N. M. C. L., Binso-Dabire, B. \& Pittendrigh, R. Effectiveness of Spinosad (Naturalytes) in Controlling the Cowpea Storage Pest, Callosobruchus maculatus (Coleoptera: Bruchidae), Journal of Economic Entomology, Volume 103, Issue 1, 1 February 2010, Pages 203-210 (2010).

40. Jian, F., Jayas, D. S. \& White, N. D. G. Can Ozone be a New Control Strategy for Pests of Stored Grain? Agric Res. 2, 1-8 (2013).

41. Giunti, G., Palmeri, V., Algeri, G. M. \& Campolo, O. VOC emissions influence intra- and interspecific interactions among stored-product Coleoptera in paddy rice. Sci Rep. 8, 2052 (2018).

42. Dong, Z. et al. Landscape agricultural simplification correlates positively with the spatial distribution of a specialist yet negatively with a generalist pest. Sci Rep. 10, 344 (2020).

43. FAO Botanical oils as grain protectants, In: The use of spices and medicinals as bioactive protectants for grains. FAO Agricultural Services Bulletin No. 137. FAO, Vialle delle Terme di Caracalla, 00100 Rome, Italy. pp239(2000).

44. Nenaah, G. E. \& Ibrahim, S. I. A. Chemical composition and the insecticidal activity of certain plants applied as powders and essential oils against two stored-products coleopteran beetles. J Pest Sci. 84, 393-402 (2011).

45. Afsheen, S. et al. Influence of cold plasma treatment on insecticidal properties of wheat seeds against red flour beetle. Plasma Science and Technology. 21, 085506 (2019).

46. Islam, M. S., Hasan, M. M., Xiong, W. \& Zang, S. Fumigant and repellent activities of essential oil from Coriandrum sativum (L.) (Apiaceae) against red flour beetle Tribolium castaneum (Herbst) (Coleoptera: Tenebrionidae). J Pest Sci. 82, 171-177 (2009).

47. Joost, G., Harnisch, R., Muck, O. \& RFG. Manual on the preservation of post-harvest grain losses. Post-harvest project,. (1996).

48. FAO Improving methods for estimating post-harvest losses

http://www.fao.org/fileadmin/templates/ess/documents/meetings_and_workshops/GS_SAC_2013/Improving_methods_for_estimating_post_harvest_los 13-13.pdf (1985)

49. Rajendran, S. Detection of Insect Infestation in Stored Foods. Advances in food and nutrition research. 49, 163-232 (2005).

50. Kyogoku, D. \& Nishida, T. The mechanism of the fecundity reduction in Callosobruchus maculatus caused by Callosobruchus chinensis males. Popul. ECol. 55 (1), 8793 (2013).

\section{Table}

\section{Table1.}

Comparison between plasma untreated and plasma-treated samples of six chickpea cultivar during 4-year storage for grain damage percentage, number of eggs/grain. Number of holes/ grain and percent grain weight loss 
Voltage (V) Exposure Time (min)

\begin{tabular}{|c|c|c|c|c|c|}
\hline$\underline{\text { Kripa }}$ & & & & & \\
\hline Control & - & $100 \pm 0.81^{\mathrm{a}}$ & $25.26 \pm 0.11^{\mathrm{a}}$ & $3.52 \pm 0.03^{\mathrm{a}}$ & $62.99 \pm 1.42^{b}$ \\
\hline \multirow{3}{*}{40} & 10 & 0 & 0 & 0 & $6.4 \pm 0.23^{\mathrm{a}}$ \\
\hline & 15 & 0 & 0 & 0 & $6.43 \pm 0.26^{\mathrm{a}}$ \\
\hline & 20 & 0 & 0 & 0 & $6.55 \pm 0.36^{\mathrm{a}}$ \\
\hline \multirow{3}{*}{50} & 10 & 0 & 0 & 0 & $4.39 \pm 0.16^{\mathrm{a}}$ \\
\hline & 15 & 0 & 0 & 0 & $6.77 \pm 0.19^{\mathrm{a}}$ \\
\hline & 20 & 0 & 0 & 0 & $6.79 \pm 0.19^{\mathrm{a}}$ \\
\hline \multirow{3}{*}{60} & 10 & 0 & 0 & 0 & $6.54 \pm 0.12^{\mathrm{a}}$ \\
\hline & 15 & 0 & 0 & 0 & $6.57 \pm 0.19^{\mathrm{a}}$ \\
\hline & 20 & 0 & 0 & 0 & $6.59 \pm 0.14^{\mathrm{a}}$ \\
\hline
\end{tabular}

\begin{tabular}{|c|c|c|c|c|c|}
\hline Virat & & & & & \\
\hline Control & - & $98 \pm 0.81^{\mathrm{a}}$ & $24.23 \pm 0.05^{\mathrm{a}}$ & $3.14 \pm 0.02^{\mathrm{a}}$ & $62.66 \pm 1.42^{b}$ \\
\hline \multirow{3}{*}{40} & 10 & 0 & 0 & 0 & $9.03 \pm 0.57^{a}$ \\
\hline & 15 & 0 & 0 & 0 & $9.65 \pm 0.83^{\mathrm{a}}$ \\
\hline & 20 & 0 & 0 & 0 & $10.52 \pm 0.81^{\mathrm{a}}$ \\
\hline \multirow{3}{*}{50} & 10 & 0 & 0 & 0 & $9.26 \pm 0.28^{\mathrm{a}}$ \\
\hline & 15 & 0 & 0 & 0 & $9.92 \pm 0.95^{\mathrm{a}}$ \\
\hline & 20 & 0 & 0 & 0 & $10.55 \pm 0.94^{\mathrm{a}}$ \\
\hline \multirow{3}{*}{60} & 10 & 0 & 0 & 0 & $9.49 \pm 0.44^{\mathrm{a}}$ \\
\hline & 15 & 0 & 0 & 0 & $10.49 \pm 0.65^{\mathrm{a}}$ \\
\hline & 20 & 0 & 0 & 0 & $12.34 \pm 0.86^{\mathrm{a}}$ \\
\hline
\end{tabular}

\begin{tabular}{|c|c|c|c|c|c|}
\hline Vishal & & & & & \\
\hline Control & - & $95 \pm 0.81^{\mathrm{a}}$ & $24.6 \pm 0.02^{\mathrm{a}}$ & $2.9 \pm 1.33^{b}$ & $62.87 \pm 1.42^{\mathrm{b}}$ \\
\hline & 10 & 0 & 0 & 0 & $8.86 \pm 0.12^{\mathrm{a}}$ \\
\hline 40 & 15 & 1 & $4.28 \pm 1.33^{\mathrm{a}}$ & $0.01 \pm 0.00$ & $8.11 \pm 0.74^{\mathrm{a}}$ \\
\hline & 20 & 2 & $5.12 \pm 1.33^{\mathrm{a}}$ & $0.02 \pm 0.00$ & $8.10 \pm 0.72^{\mathrm{a}}$ \\
\hline & 10 & 0 & 0 & 0 & $8.04 \pm 0.58^{\mathrm{a}}$ \\
\hline 50 & 15 & 0 & 0 & 0 & $7.15 \pm 0.13^{\mathrm{a}}$ \\
\hline & 20 & 0 & 0 & 0 & $8.00 \pm 0.59^{\mathrm{a}}$ \\
\hline & 10 & 0 & 0 & 0 & $8.02 \pm 0.47^{\mathrm{a}}$ \\
\hline 60 & 15 & 0 & 0 & 0 & $7.54 \pm 0.33^{\mathrm{a}}$ \\
\hline & 20 & 0 & 0 & 0 & $7.56 \pm 0.30^{\mathrm{a}}$ \\
\hline Plas & ma Treatment & Grain damage (\%) & Number of eggs/grain & Number of holes/grain & Grain weight loss (\%) \\
\hline Voltage $(\mathrm{V})$ & Exposure Time (min) & & & & \\
\hline$\underline{R a j} \underline{j a s}$ & & & & & \\
\hline Control & - & $97 \pm 0.81^{\mathrm{a}}$ & $25.44 \pm 0.02^{\mathrm{a}}$ & $3.12 \pm 0.05^{\mathrm{a}}$ & $62.87 \pm 0.69^{b}$ \\
\hline & 10 & 0 & 0 & 0 & $11.30 \pm 0.69^{\mathrm{a}}$ \\
\hline 40 & 15 & 0 & 0 & 0 & $12.46 \pm .17^{\mathrm{a}}$ \\
\hline & 20 & 0 & 0 & 0 & $12.30 \pm 0.91^{\mathrm{a}}$ \\
\hline & 10 & 0 & 0 & 0 & $13.71 \pm 0.87^{\mathrm{a}}$ \\
\hline 50 & 15 & 0 & 0 & 0 & $12.49 \pm 0.37^{b}$ \\
\hline & 20 & 0 & 0 & 0 & $13.13 \pm 0.58^{\mathrm{a}}$ \\
\hline & 10 & 0 & 0 & 0 & $14.83 \pm 0.71^{\mathrm{a}}$ \\
\hline
\end{tabular}


All the data are expressed as mean \pm standard error. Means with the different superscript letters in a column differ significantly $(\mathrm{P}<0.05)$

\section{Figures}

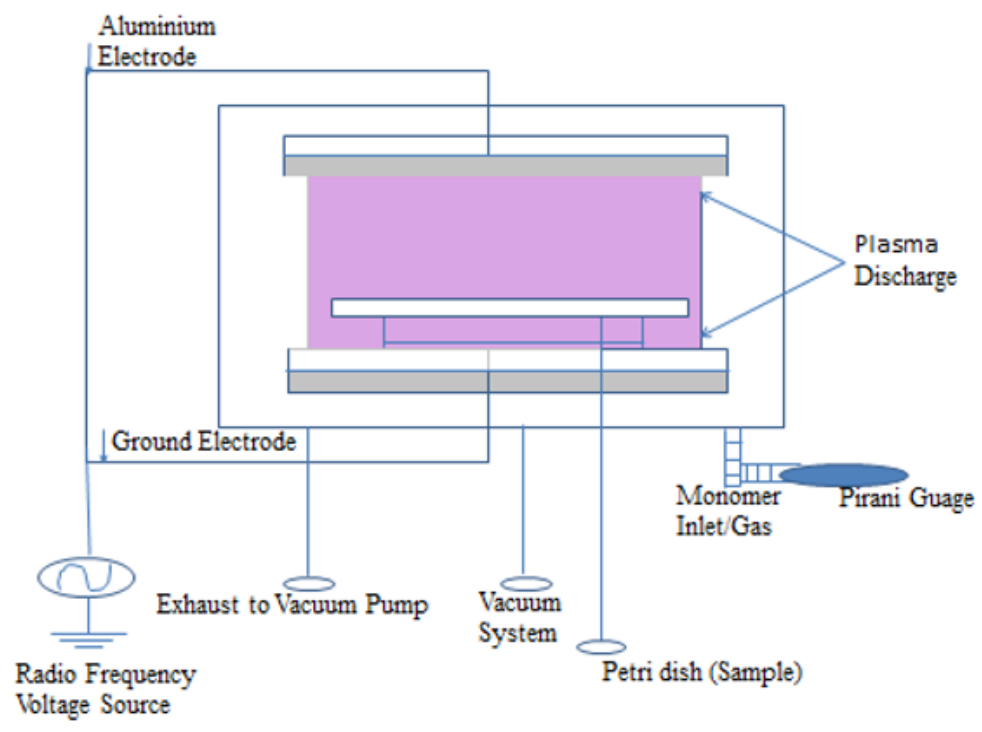

Figure 1

Schematic diagram of the low-temperature plasma system

\section{Supplementary Files}

This is a list of supplementary files associated with this preprint. Click to download.

- SupplementaryFigureS1.pdf

- SupplementaryFigureS2.pdf

- SupplementaryFigureS3.pdf

- SupplementaryFigureS4.pdf

- SupplementaryTables1.pdf

- SupplementaryTables2.pdf

- SupplementaryTables3.pdf

- SupplementaryTables4.pdf 